\title{
A Local Computerized Multi-screening of Vast Amount of Data to Select Hydraulic Fracturing Candidates in Iranian Carbonate Oil Fields
}

\author{
Abolfazl Hashemi \\ National Iranian Oil Company, \\ Arvandan Oil \& Gas Company, \\ Khoramshahr, Iran
}

\author{
Seyed Reza Shadizadeh \\ Petroleum University of Technology \\ Abadan faculty of petroleum \\ Engineering, Abadan, Iran
}

\author{
Mansoor Zoveidavianpoor \\ Universiti Teknologi Malaysia \\ Faculty of Petroleum \& Renewable \\ Energy, Johor, Malaysia
}

\begin{abstract}
Iranian oil companies are developing the technique of Hydraulic Fracturing (HF) operation to enhance the hydrocarbon recovery of deep carbonate formations. However, there is not a computerized tool or well defined framework for Iranian carbonate oil fields to select candidates. The ineffective HF experiences in the past emphasized that candidate selection is the frontline of a victorious HF operation. This paper presents the development of a local programme to automatically select specific zones for special purposes like HF. The program is written in MATLAB in such a way to integrate large amount of data from different disciplines. In addition, the missing data are compensated with Neural Network and Fuzzy Logic techniques. In the end data are mechanically screened based on the user selected parameters, cut-offs and weight factors. Results of screening within the limitations are prioritized in stacked bars to make decision easier. This tool is applied for a purpose of candidate selection for HF in $\mathrm{M}$ oil field located in south of Iran. This field has 585 zones which each zone has more than 30 parameters form different disciplines. The result of this programming is printed schematically and it is conclusive to our clients.
\end{abstract}

\section{General Terms}

In this paper, a comprehensive algorithm for candidate selection is defined and a local multi screening program is introduced.

\section{Keywords}

Candidate Selection, Carbonate Formation, Hydraulic Fracturing, Mechanical Screening, Iran.

\section{INTRODUCTION}

Iran is producing oil for more than 100 years and most of the fields are mature and it is estimated that 200,000-250,000 $\mathrm{bbl} / \mathrm{d}$ of crude production be lost annually due to natural pressure declines of the fields (EIA, 2007). Moreover, with available technology, it is only possible to extract $20 \%$ to $25 \%$ of the original oil in place from Iranian carbonate oil reservoirs, which is $10 \%$ less than the world average. Therefore, looking for new technology to maintain and increase the production is inevitable. HF technology is introduced as an effective approach that can make the difference and can grant new life to old mature fields (Martin and Raylance 2010). Various advantages make HF a superior type of production enhancement in carbonate reservoirs. This subject along with the needs for HF was addressed briefly by
Zoveidavianpoor et al. (2010, 2011b). Although HF operation has more than 60 years of history and every day hundreds of treatment is performed around the globe, however, there is not any report of prosperous HF operation in Iran. In order to have well-adapted HF technology in Iran, detailed geomechanical studies and well integrity test such as leak-off test, minifrac test, calibration test, etc., have to be performed. Unfortunately, those bottom-line studies are not implementing in Iran. These crucial disadvantages were addressed in references Shadizadeh and Zoveidavianpoor, 2010; Zoveidavianpoor et al. 2011a. Generally, lack of data/information about rock mechanical properties, regional in-situ stress, and specially no consideration of candidate selection study, were the main reasons of failure in HF operation.

Iranian oil companies are lately expected to develop technologies like HF to extract more oil from down deep reservoirs. It is clearly indicated in HF experience's literature, to be successfully conducted, it is primarily depending on systematic candidate selection. The disappointment of a single case of HF in southern Iranian oilfield indicates that to accept $\mathrm{HF}$ technology as a replacement stimulation method and also, increasing the recovery factor, significant efforts have to be concentrated on zone and well candidate selection. As a result, a research project has been proposed and started in National Iranian South Oil Company (NISOC) to investigate candidate selection for HF in three oilfields named: "A", "M", and "AR".

This paper presents the development of one local efficient tool to determine the best HF candidate well in "M" oilfield in south of Iran. A multidisciplinary team was set up with engineers and scientists from reservoir and production engineering, geologist, and computer engineers. The methodology will consider all the available data to select high-potential candidate zones and wells in a trustworthy manner. This method demonstrates in one flowchart and involves three steps. First, all required data, including reservoir, production, geology, and petrophysics, had systematically collected in a database. Secondly, the critical criteria are investigated through different approaches. Third, screening is performed to select the candidate. The results will go for HF design and field practice. This methodology is examined in "M" oilfield and the results are demonstrated. The comprehensive screening based on selecting criteria and special graphical demonstration makes the selections trustworthy for oil companies. 


\subsection{Oilfield Description}

The investigated oilfield is located $40 \mathrm{~km}$ south of Ahwaz city in Khuzestan province, along with, "AR" oilfield. This field located neighbors with "A" oilfield to the North, "AR" to the West. Generally, $\mathrm{M}$ oilfield includes two types of reservoirs; Asmari and Bangestan. The first was explored by well No.1 in 1963. The later consist of two oil bearing formations; Ilam \& Sarvak. Ilam formation is divided to 3 subzones and Sarvak is consisted of 10 subzones. The focus of this paper is on Bangestan reservoir, which has 42 wells and each well has 13 zones. The current production of Bangestan is above 50,000 barrels per day with average reservoir pressure of $4800 \mathrm{psi}$.

The total producing wells in Ilam formation are 10 wells that contributing to a $37 \%$ of the total Bangestan reservoir in " $\mathrm{M}$ " oilfield. On the other hand, $62 \%$ of the total production comes from 32 wells of Sarvak formation. Most wells completed in Ilam, and Sarvak are vertical wells that have a single completion to produce from a horizon. The average producing intervals are 200 and 30 meters in Sarvak and Ilam respectively. A total of 10 wells in Bangestan reservoir had problems of asphaltene precipitation and high water cut. In some of the wells, sand was produced as rock fragments.

\subsection{Candidate Selection Methodologies Literature Review}

The book published by Economides and Nolte (2000) is the frontier in reservoir stimulation methodologies. They presented the flowcharts of candidate selection mainly for matrix stimulation and frequently emphasized the role of candidate selection in successful stimulation operation. Burnstad et al. (2004) cited that the candidate screening and selection was a vital part of the treatment process and evolved over the first few years of the fracturing operations and were continually improved throughout the redevelopment. They started the process of candidate screening and selection with Reservoir Engineering reviewing reservoir parameters and potential oil gains. The prioritized list was then sent to Production Engineering, where the potential well candidates were further screened and prioritized. They ended up with 20 candidates and began the well treatment in series. They applied the learned lessons to revise the priority list of candidate as well as improving the fracture designs and well operations. Some authors like Bagzis et al (1998) gave cut off values to some key parameters to indentify interval selection. Moore and Ramakrishan (2006) presented that in other fields like, Sinopec Xinchang gas reservoir in China, the preliminary candidate selection methodology involved a weighted parameter approach. Bustin and Sierra (2009) discard the candidate if the well already acid stimulated or does not have timely production logging tool (PLT) data.

Martin and Raylance (2010) alleged there is no one-size-fitsall approach as a process and certainly no single consideration exists to provide the $100 \%$ solution for HF candidate selection. They illustrated that successful candidate selection for $\mathrm{HF}$ requires the consideration of all the opportunities available on three-distinct scales, which they defined as: Regionalized (Macroscopic), Neighborhood (Mesoscopic) and Localized (Microscopic). The Regional Considerations consists of Reservoir Heterogeneity, Reservoir Continuity, Geographic Information Systems and Gathering and Production. Neighborhood considerations are Offset Well Performance, Drainage Shape and Area, Areal Connectivity and Publicly Available Data. And Local level consists of Reservoir Characteristics, Pressure Transient Analysis,
Production History Matching and Mechanical Integrity. In other effort Moore and Ramakrishan (2006) presented a framework for restimulation candidate selection as a comprehensive approach by Schlumberger Data and Consulting Services. After literature review, the Moving Domain Analysis (MDA) and performance based screening are applied to eliminate the no promising wells. Furthermore, they have reviewed the well public data and production history to find the key drivers and indicators to rank the wells. The top candidates will go for integrated evaluation methodology to verify the key drivers. After restimulation the results will be applied to tune the selection process.

In other point of view Martin and Economides (2010) pointed on the fact that the main limitations to candidate selection are not the technical aspects of reservoir and fracture performance. Instead, more mundane reasons may cause an interval or a wellbore to be rejected as a candidate for hydraulic fracturing. They introduced a list of reservoir and well mechanical considerations. They also demonstrated that treating one good performance well may give much more production than couple of poor wells.

As Mohaghegh et al. 2005 cited, when the volume of data increases, human cognition is no longer capable of deciphering important information from it by conventional techniques. He demonstrated that data mining and machine learning techniques must be used in order to deduce information and knowledge from the raw data that resides in the databases. They invented the technique of Intelligent Best Practices Analysis to deploy large amount of data to increase the efficiency of the operations. They systematically analyzed data to decipher and deduce relevant knowledge in order to be used in business and engineering decision making. Their method incorporates a hybrid form of intelligent systems that includes artificial neural networks, genetic algorithms and fuzzy logic to achieve its objective.

As it is obvious in the literatures several strategies are presented for candidate selection and they are not sound explained in detail and mainly covering the candidate selection for restimulation purposes. However, the Iranian oil companies are in the initial steps of HF stimulation and as a result the first challenge is to develop a local methodology to incorporate all available data to select candidates. There are lots of hydrocarbon producing fields, penetrated with hundreds of wells and each well has numerous productive zones, therefore the amount of data are out of imagination. To decipher this volume of data and conclude the best candidates needs a systematic methodology to incorporate all available data. And ever since, there was not any systematic comprehensive methodology for recognizing primary candidates. The aim of this paper is to present a locally adapted methodology and a program to screen and select candidates for HF operation. The methodology can be applied easily in every field or couple of field at the same time. However in this study only the results of candidate selection in " $\mathrm{M}$ " field are presented.

\section{METHODOLOGY}

Quite a lot of efforts and involving different disciplines directed to a local methodology shown in Figure 1 as shown in the flowchart, the selection and screening is divided into two paths. In one path, all zones are processed and in the other one, well data are examined. For zone selection practice, in the first step all zone data including regular log data, petrophysical data, bottom hole pressures, likely Dipole Sonic Information (DSI) log and etc. are collected in separate excel 
sheets with specified formats. One advantage of this program is that any data like completion status, flow dynamic data, which can be attributed to one zone, also can be included. Some data may not be available, for instance, due to high cost, DSI log is run in just one well in a field or in adjacent fields and the results are duplicated for other wells. But, even if the formations are the same, it is not quite correct to copy paste the DSI log to other wells. Therefore, Fuzzy Logic and Neural Network are employed to train by available log data and distribute the correlated results to other wells. At this point when all wells have the same amount of data, then different stress profiles can be calculated in all wells. Due to lack of minifrac test in most Iranian oil fields, therefore, it is necessary to find a correlation for stress calculation. Different well known correlations are considered and the program automatically chooses the best correlation to determine the final stress profile. In addition, through interpolation or extrapolation, for each depth every property is quantified and all zones' data will be integrated and printed to one excel sheet. There is also a possibility to define the data within specified zones or any user defined intervals.
In the next step the critical criteria, their limits and their weight factors are provided by user. To continue the process, there are two approaches. If there is a successful treatment formation log available, then the program can find the same formation through comparing two logs with the same properties. Otherwise the mechanical screening option will be recommended. In the end the prioritized zones are shown in stacked bars. More or less the same process is applied for well selection path, however just mechanical screening can be performed to reach the list of well candidates. In the end, the incorporation of zone candidates and well candidates will grant the best well for designing preliminary HF treatment. To practice the design in the field, one calibration test is required to make sure the operation is performed without unpredicted problem. The field calibration may finalize the HF design or may feedback the process of selection by defining new criteria and limitations.

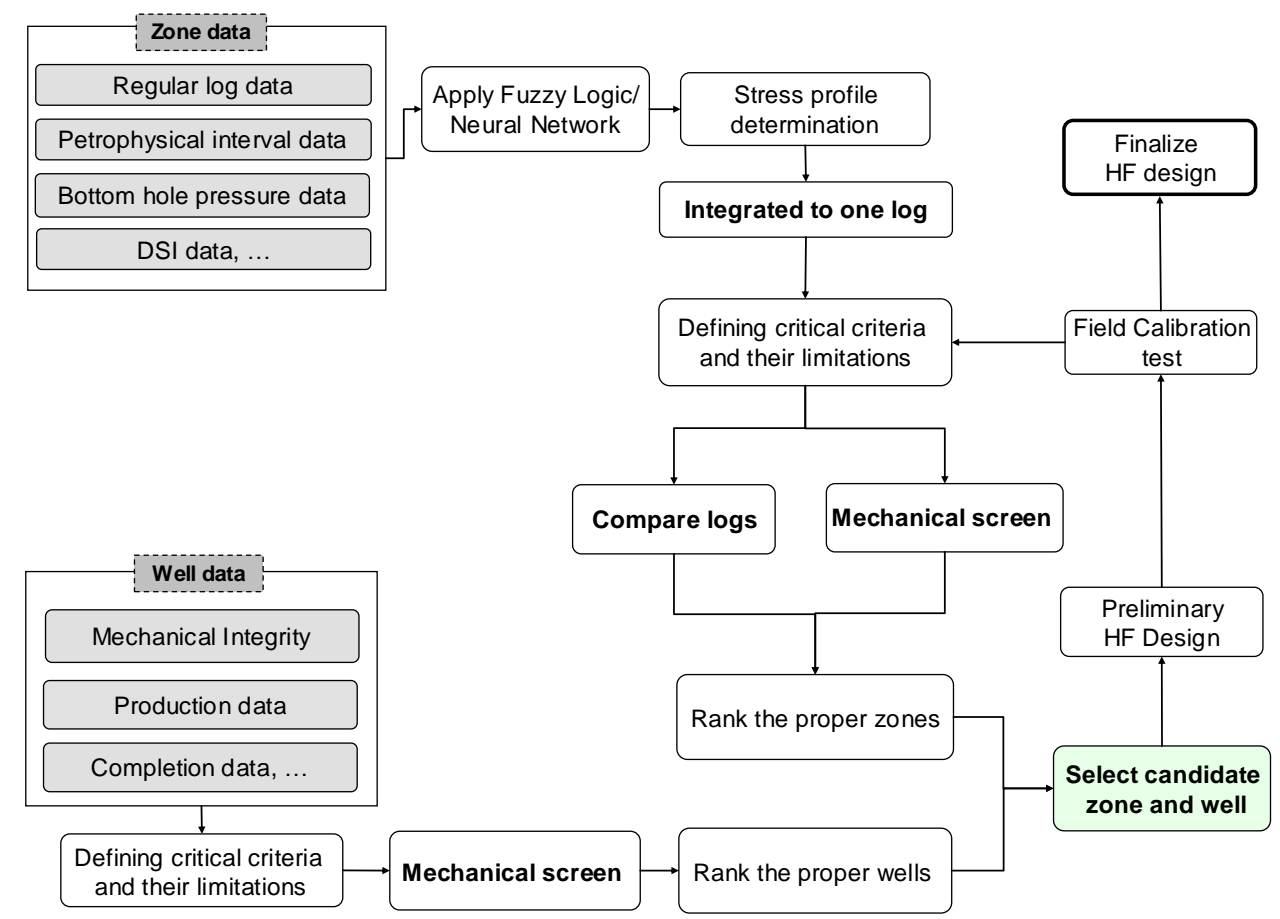

Figure 1: Schematic of candidate selection procedure in the programmed tool

\subsection{Application of Fuzzy Logic and Neural Network}

In $\mathrm{M}$ field some data is not available in all wells. For instance rock mechanic (DSI) $\log$ is available in just one well, or permeability data is available in some wells. To copy the existing $\operatorname{logs}$ to other wells could make significant error especially in stress profile determination because rock mechanic properties of one zone, which is affected by environmental factors, can be variable all along the reservoir. Application of soft calculations in prediction of formation rock properties has been practiced by several authors. Abdulraheem et al. (2009) applied three artificial intelligence methods viz. Neural Network, Fuzzy Logic and Functional
Network to obtain a continuous profile of static elastic parameters along the depth.

Steve Cuddy (1997) relies on basic log data sets such as gamma-ray and porosity to employ fuzzy logic to predict the lithofacies and permeability. Shokir (2004) successfully developed a fuzzy model to estimate permeability of uncored wells in heterogeneous oil reservoirs using core porosity and gamma ray logs. Mohaghegh et al. (2004) used combination of fuzzy logic and neural networks to determine the in-situ stress profile of hydrocarbon reservoirs from geophysical well logs. Moreover, Cheng-Dang et al. (1994) identified oil from well $\log$ and distinguished oil, water, oil-water transitioned dry zones directly from well log by application of neural network and fuzzy logics. 
Therefore to assign the rock mechanic data to formation logs in $\mathrm{M}$ field, the application of Fuzzy logic and Neural Network worked out by applying predefined MATLAB codes. The genfis 2 command of MATLAB is employed to generate a Sugeno-type Fuzzy Inference System (FIS) from data which uses the subtractive clustering method. In this way genfis 2 command is applied on training data to generate an initial FIS for anfis training. The anfis uses a hybrid learning algorithm to identify parameters of Sugeno-type fuzzy inference systems. It applies a combination of the least-squares method and the back propagation gradient descent method for training FIS membership function parameters to emulate a given training data set. Then evalfis command is applied to evaluate a fuzzy system for given inputs. The fuzzy structure was tested with available DSI log and the results are quite satisfactory.

Moreover, newfit MATLAB command is utilized to create a fitting neural network with fifty hidden neurons. The created network is trained by available input and target data. In the end the sim command is used to predict output from input data

Special windows were designed for Fuzzy logic and Neural Network applications. Two logs are loaded in a window and the same properties in both logs are given the same numbers, however the rock mechanic value in one log is given different number. The program will identify and try to correlate the rock mechanic data of one $\log$ to the other. Although the results of both fuzzy logic and neural network follow the same trend but the best reasonable results are selected. As a result the Poisson's ratio and Young's modulus from one well is distributed to other wells. It is worth mentioning, that in all this estimations the contrast is more important than the exact value of a property. In other word, it is not important to find out the exact rock mechanical value of a zone, but the changes of the property in comparison with adjacent zones are more important. Since the zones are measured up to each other and then prioritized therefore these methodologies are quite helpful to compensate the missing data.

\subsection{Stress Profile Determination}

One of the main efforts of this computerized candidate selection for HF is the ability to build the accurate stress profile. The well predicted stress profiles can grant the fracture initiation, development and confinement in the target zone. It has been reported that lack of accurate in-situ stress values during the design of a hydraulic fracture can result in as much as $50 \%$ error in the actual fracture length upon implementation (Mohaghegh et al. 2004). To practically develop a minimum stress model for deep carbonate formation needs lots of leak off or minifrac tests. However, due to risk and cost involvement, just a few such data are practiced in field operations.

There is specifically one leakoff test in one well in "M" oil field. Therefore, it was expected to look for a correlation to match the existing leakoff data. There are lots of developed correlations around the world. The minimum horizontal stress correlations of Eaton (1969), Zamora (1989), Koceir et al. (2000), Constant et al. (1988), Pilkington (1978), Holbrook (1993), Anderson et al. (1973), Brennen et al. (1984) and Morales (1989) investigated. Part of the program is automatically examined any input correlations and calculate the matching error with practical data. In this particular field, minimum error reflected that Eaton equation has the best match. This result is in complement with achievement of Shadizadeh et al. (2009a, 2009b) and Sanaee et al. (2010). Therefore in our program Eaton equation is applied to calculate the in-situ stress in all the wells. Figure 2 is demonstrating average stress profile based on Eaton correlation and also young's modulus in well\#6. As shown the well has 13 zones and the contrasts of the stress value of each zone with adjacent zones are quite obvious. No consideration of other parameters but just stress profile, one can easily recognize a target zone (as shown with green color). A low stress zone surrounded with high stress zones can control the fracture confinement and propagation. As shown in Figure 2, zone number 6 has favorable stress contrast and also has comparatively low young's modulus. Low Young's modulus can lead to wide enough fracture.

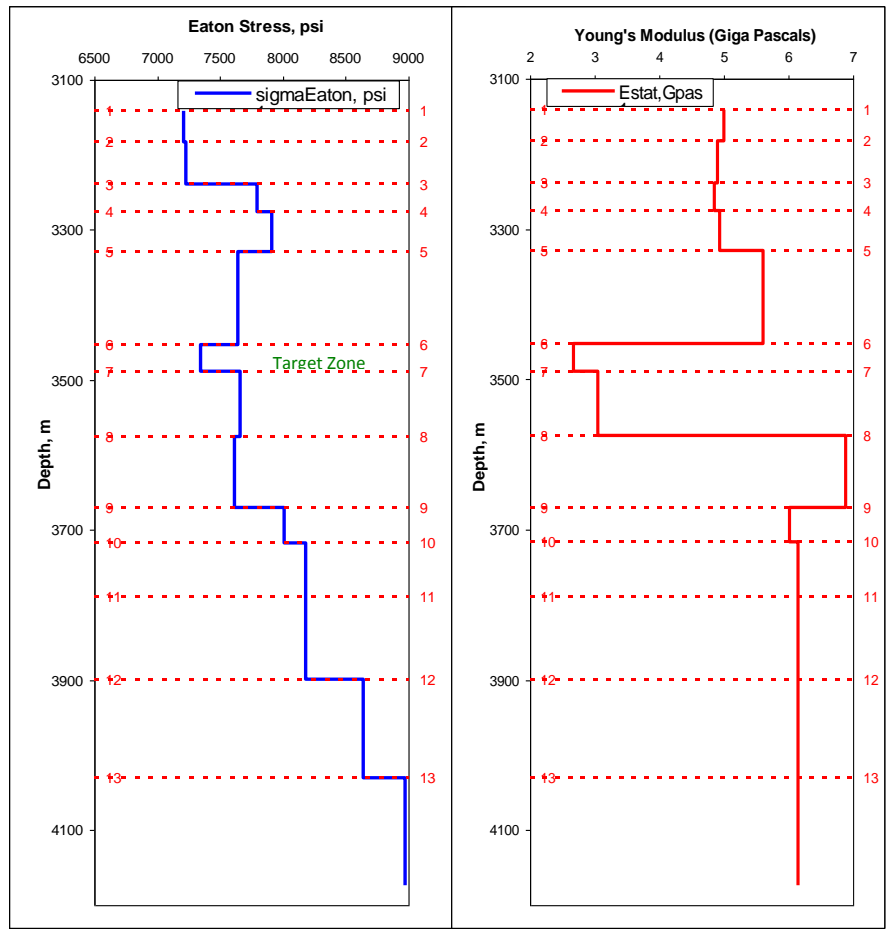

Figure 2: Stress profile and Young's Modulus in Well\#6.

\subsection{Define Critical Parameters and Their Limitations}

To choose the best screening criteria is the key challenge. When all data collected from different excel sheets and integrated to one sheet, then the program will prompt the header of the data in checkboxes. The user can click and choose the screening criteria. However, which parameters should be chosen or how much is the effect of each parameter on the result. This question can be answered by field experiences, literature reviews and software application. Since there is not any practice of hydraulic fracturing in this or similar oil fields, therefore the other two approaches should be followed. Extensive literature review performed and vital parameters extracted from comparable case studies. Survey was done not only on factors which are under the control of the engineers but also on other innate properties like rock properties. The results of study will be published in near future, but the main results were localized and based on available data, they are applied as candidate selection criteria. However, there are two phenomena specifically for carbonate rocks; first is multiple fracture occurrence due to highly heterogeneous nature of carbonates, and second is the possibility of screen out phenomena due to formation high Young's modulus. 
It seems for Iranian carbonate rocks, zones with enough production potential and far from oil water contact are profitable case and to prevent multiple fracture enhancements, net thickness of the zone should be well selected. Moreover, fracture confinement due to stress contrast between target zone and upper and lower zones should be considered.

To carry out software application, fracturing a zone with hydraulic fracturing software, called FracPORO is used. The model of well\#6 was built in FracPORO. Zone number 6 selected as the target zone (shown in Figure 2). The properties of this zone along with some fluid properties are brought together in Table 1 . The pumping schedule of this model was tuned to get the fracture half length of 150 meter. This model is named base case. Furthermore, the effect of different input parameters on fracture half length is analyzed. Length of fracture half length has direct relation with zone productivity, i.e. longer fracture can provide more hydrocarbon production. The selected input data are: zone thickness, Poisson's ratio, permeability, specific gravity, total compressibility, young's modulus, porosity and dolomite percentage, target zone stress gradient, stress gradient of the zone below target zone and stress gradient of the zone above target zone. The values of these input data are changed by 50,20,10 percents in positive and negative direction and then the model is run for each change. The fracture half lengths of these new models are compared with the base case. The results are depicted in Figure 3. As can be detected in the figure, Zone Thickness, Young's Modulus, Zone Stress and Stress contrast of target zone with upper and lower zone have the most effect on fracture half length. Other parameters do not have considerable effect on fracturing length. Since this kind of software is made based on real field data, therefore the importance and also weight of each parameter on candidate selection can be recognized. Based on the results shown in the figure, increase in stress gradient, young's modulus and zone thickness of the target zone reduces the fracture half length. However, the reduction of these parameters increases the fracture half length. Among these parameters, zone stress has the most effect and zone thickness has least effect on fracturing elongation. Moreover, reducing the stress of the lower and upper zone can dramatically reduce the fracture half length. In addition, increasing lower zone stress has no effect however upper zone increment to a certain extent can increase the fracture half length. Other parameters do not have significant effect on fracture half length.

Table 1: Rock properties of target zone in Well\#6

\begin{tabular}{|l|l|}
\hline Property & Value \\
\hline Zone Thickness, $\mathrm{m}$ & 24 \\
\hline Poisson's Ratio & 0.28 \\
\hline Permeability, md & 9 \\
\hline Specific Gravity & 2.55 \\
\hline Total Compressibility, $1 / \mathrm{kpas}$ & $1 \mathrm{e}-6$ \\
\hline Stress gradient, kpa/m & 15.4 \\
\hline Stress Gradient Lower zone, $\mathrm{kpa} / \mathrm{m}$ & 16.3 \\
\hline Stress Gradient Upper zone, $\mathrm{kpa} / \mathrm{m}$ & 16.4 \\
\hline Young's Modulus, Gpa & 2.67 \\
\hline Porosity, $\%$ & 8 \\
\hline Percent Dolomite & 10 \\
\hline Water Saturation, $\%$ & 29 \\
\hline Oil Saturation, $\%$ & 71 \\
\hline Bottom Hole Static Temperature, ${ }^{\circ} \mathrm{F}$ & 220 \\
\hline Oil API gravity & 25 \\
\hline Solution Gas Oil ratio, scf/stb & 390 \\
\hline Bubble point pressure, psi & 1560 \\
\hline Water gravity & 1.17 \\
\hline Gas gravity & 0.7 \\
\hline & \\
\hline
\end{tabular}




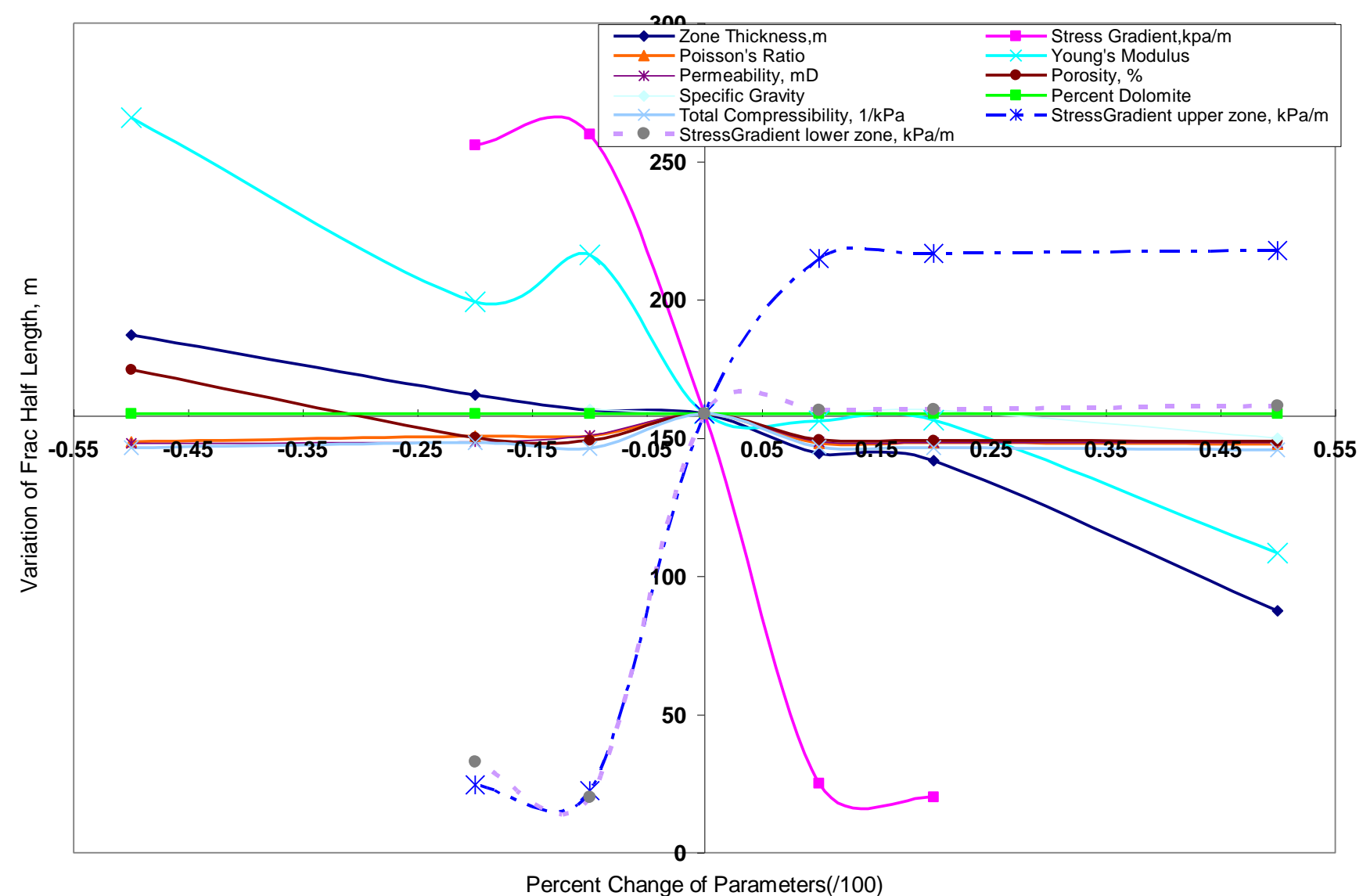

Figure 3: Sensitivity Analysis of input parameters on frac half length.

\subsection{Compare logs to identify similar zones}

There are lots of well logs in all oil producing companies. Sometimes it is needed to compare one log with others to find the same zones. For instance, if hydraulic fracturing implemented successfully in one zone, then it is very helpful to have a tool to find the same zone with the same characteristics in other wells or fields. We have developed a program to systematically compare two logs to find the same zones with the matching properties. A special window designed in such a way to browse two logs and allocate the same numbers to the same properties in two logs. The program will compare two logs within a predefined range of dissimilarity and will print the same zones in two logs. Of course there are currently commercial softwares that can correlate the zones from well to well, but this program is more flexible and adapted for choosing any number of input parameters and their range of dissimilarity.

$\mathrm{HF}$ operation is frequently practicing in neighborhood countries which have more of less the same oil bearing zones. But, unfortunately, in their literatures there are not cases of carbonate HF treatments with complete logs. In some literatures there are logs but there was done minor repairs on data. If there was any case, it would be easy to apply this section of program to find the same zone among Iranian carbonate formations. Therefore the usage of this section of the program is maintained for future applications.

\subsection{Mechanical Screening}

All zone properties are collected in one excel sheet and for each depth, there is lots of information involving, log data, petrophysical data, static pressure data, dynamic properties (like permeability), rock mechanical characteristics (DSI data) and even the completion status (like cement quality if cased hole). The program will read the header and expose it to the user through checkboxes. User should select important parameters by clicking the related checkboxes. In the next window two scroll bars for each parameter is appeared. The minimum and maximum value of each parameter defines the scroll bar range. One scroll bar can be used to define the lower limit and the other one can define the upper limit. The users can narrow the screening window by moving the scrolls. After setting a window for each parameter, then screening of zones is started. The programme will examine all the zones to find the candidate with predefined conditions. When all the zones are recognized, then the candidates will be sorted by their aptness. This operation can be run in a loop for any number of wells. The well selection is carried out with the same procedure. The result of these two screening will commingle to find the best zone in the best well for HF operation.

\section{RESULTS}

Figure 4 and Figure 5 are the results of zone and well screening. Figure 4 is the results of zone screening in "M" carbonate oil field. In the left of the figure the screening criteria, their limitations and their weight factor (wt) are demonstrated. Based on the Literature reviews, software application and available data, the following criteria are selected: 1) Net Thickness, m (net pay zone), 2) Sw_Ave (average water saturation), 3) So_Ave (average oil saturation), 4) ProdShare, \% (production sharing of the zone), 5) toOWC, 
m (remoteness of a zone to oil water contact), 6) E, Gpas (young's modulus), 7) StressContUp, psi (stress contrast of target with upper zone), 8) StressContLow, psi (stress contrast of target with lower zone). The limitations of these parameters are demonstrated against them and weight factor of one is set for all. In the right is the stacked bar of the candidates. The number of colors is equal to the number of criteria. The length of each color demonstrates how far a special property is from limit setting. Furthermore, longer bars mean more appropriate candidate. As indicated in Figure 4 by considering the available data and defined criteria, first candidate is zone number 9 in well number 20, second is zone number 9 in well number 19 , third is zone number 9 in well number 25 , fourth is zone number 6 in well number 6 and the last priority is zone number 9 in well number 4 . Although candidate zones have been identified, but the final candidate should be reported when the results of well screening is completed as well.

\section{Well,Zone Screened Ranked: 1cl=wellnum, $2 \mathrm{cl}=$ zonenum}

\begin{tabular}{|l|c|c|c|c|c|}
\hline NetThickness,m & $<$ & 70.3476 & 0 & Wt & 1 \\
\hline Sw-Ave & $<$ & 0.30256 & 0 & Wt & 1 \\
\hline So_Ave & $>$ & 0.504 & 0.504 & Wt & 1 \\
\hline ProdShare,\% & $>$ & 0 & 0 & Wt & 1 \\
\hline toOWC,m & $>$ & 23.3548 & -630.23 & Wt & 1 \\
\hline Estat,Gpas & $<$ & 8.00557 & 1.58608 & Wt & 1 \\
\hline StressContUp_psi & $<$ & -204.139 & -672.353 & Wt & 1 \\
\hline StressContLow_psi & $<$ & -113.061 & -942.179 & Wt & 1 \\
\hline
\end{tabular}

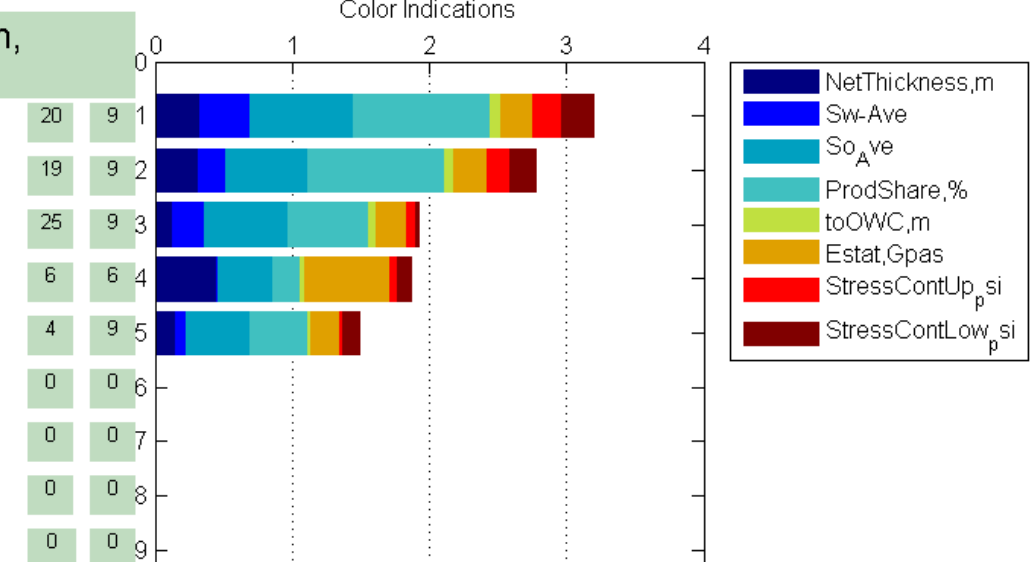

Figure 4: Outcome of the tool for zone candidate selection

Figure 5 shows the results of well screening. In the left of the figure the screening criteria are sketched. Based on the discussions and available data, the following criteria are specified: 1) PI test (bbl/day/psi), Productivity Index, 2) S, skin factor, 3) K (md), permeability, 4) SBHP (psi), Shut in Bottom Hole Pressure. The limitations of these parameters are demonstrated against them and weight factor of one is set for all of them. In the right is the stacked bar of the well candidates. The number of colors is equal to the number of screening criteria. Longer bars mean more appropriate candidate. As shown in the figure by considering the available data and defined criteria, well numbers $23,6,37,25,33,4,16$ and 15 are appropriate for HF operation.

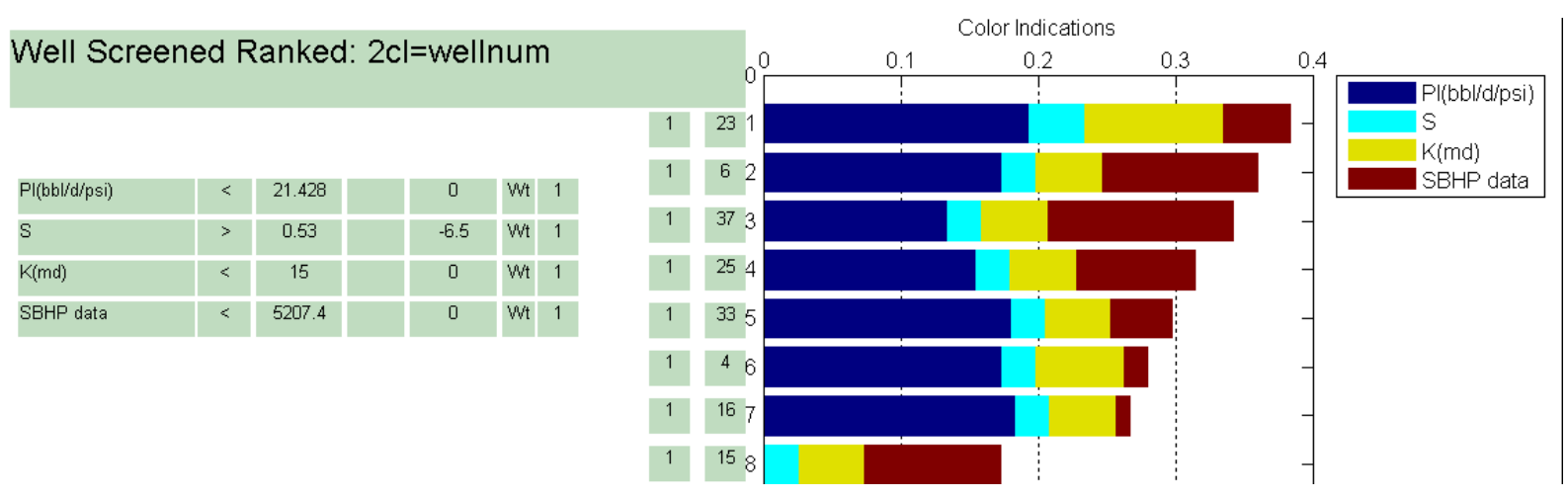

Figure 5: Outcome of the tool for well candidate selection

In the end, the results of zone screening and well screening are commingled to grant one zone in one well for initiation of hydraulic fracturing design. Comparing zone and well screening shows that by considering the available data and criteria, zone number 6 in well number 6 is the final candidate for hydraulic fracturing design and subsequent treatment.

\section{DISCUSSIONS}

In the literatures there are lots of approaches to choose a candidate and in most cases restimulation candidate selection is discussed. Whereas, in $\mathrm{M}$ oilfield, the first hydraulic fracturing is going to be designed and the prosperity in primary jobs can have huge effect on reserve and future field development. But no local selection strategy or tools has been developed to choose a zone among hundreds in Iranian Carbonate reservoirs. Choosing the first candidate for $\mathrm{HF}$ would be a challenging and perplexing task, especially when most chance of success or failure of the treatment is very much depended on it. Although there are lots of factors involved in the success of HF operation, but in the front line is the candidate selection. To carry out the candidate selection in $\mathrm{M}$ field, an integrated method based on the local condition of 
the cased study, had been performed. A MATLAB code has been written to first prepare data of each zone, compensate the missing data and then perform a mutli-screening on userselected data to choose the candidates. All data of 585 zones are considered. The results schematically show the prioritized list of candidates and the commingling the results of zone and well selection can introduce the best candidate for the very first HF treatment designs. In M field zone number 6 in well number 6 candidated for the firs HF field practice.

\section{CONCLUSIONS}

1. One local computer program is written to worth the value of vast amount of existing data. Different data from different depths are systemically integrated and required information and knowledge are deduced. Moreover the program can decipher and analyze enormous data to choose a candidate with predefined criteria. Since the program can just recognize the numbers, therefore any qualitative information should be quantified to be analyzed by the program.

2. Based on the local condition and available data one comprehensive screening flow chart was devised. The Toolbox of Graphical User Interface (GUI) in MATLAB software is utilized to write the program to go through the flowchart and select the candidate for hydraulic fracturing design. The program is able to compensate the missing data with the help of Fuzzy logic and Neural Network. Moreover, comparing logs is also applicable for finding the same zones in two wells. All collected data in excel sheets, is introduced to the user. And user can choose the selection criteria and their limitations. In the end, the effectiveness of each parameter is graphical demonstrated and makes the decision making much easier.

3. The outcome of this procedure can be granted, since all zone and well parameters are considered. Moreover the written program is just a versatile tool to systematically apply large amount of data and depends on the accuracy of input data, trustworthy candidates are selected.

\section{ACKNOWLEDGMENTS}

This paper is the results of the research project funded by Research and Development (R\&D) Department of National Iranian South Oil Company (NISOC). The authors wish to express gratitude to R\&D of NISOC for preparing the opportunity to do this research study and support during the course of this work.

\section{REFERENCES}

[1] Iran Oil, Country Analysis Briefs. US Energy Information Administration, 2007. http://www.eia.doe.gov/emeu/cabs/Iran/Oil.html.

[2] Martin, A. N. and Raylance, M., 2010, Hydraulic Fracturing Makes the Difference: New Life for Old Fields, SPE 127743, presented at the SPE North Africa Technical Conference and Exhibition held in Cairo, Egypt.

[3] Zoveidavianpoor, M., Shadizadeh, S.R. and Mombeini, S., 2010. Evaluation and Improvement of Well Stimulation by Matrix Acidizing in one of the Southern Iranian Oilfields, Petroleum Research, 20: 62, 94-106.

[4] Zoveidavianpoor, M., Samsuri, A. and Shadizadeh, S.R. 2011b. The Needs for Hydraulic Fracturing in Iranian Carbonate Oilfields: Acid or Propped Fracture?
Presented in The First National Conference of Novel Technologies in Oil \& Gas Industries, IAU.

[5] Shadizadeh, S.R. and Zoveidavianpoor M. 2010. Study reviews Iran, world well cementing practices, Oil \& Gas Journal, 108: 22, 43-51.

[6] Zoveidavianpoor, M., Samsuri, A. and Shadizadeh, S.R. 2011a. Leakoff Test in the Drilling Operation of oil and gas wells: Effective and Important in the Whole Petroleum Engineering's Disciplines, Presented in The First National Conference of Novel Technologies in Oil \& Gas Industries, IAU.

[7] Economides, M.J. and Nolte, K.G. 2000. Reservoir Stimulation. 3rd ed. Chichester, England, UK: John Wiley \& Sons Ltd.

[8] Burnstad, R.G., Martin, A.N., Stemberger, D.J. and Purwanto, B. 2004. A Case Study of a Mature Field Redevelopment Using Propped Hydraulic Fracturing, SPE 88604, presented at the SPE Asia Pacific Oil and Gas Conference and Exhibition held in Perth, Australia.

[9] Bagzis, J.M., Wehunt, C.D., Neubauer, E.B., Jansson, R.P., Tjoonk,R., Roueche,L.N. and Scarborogh, B. 1998. Optimized Hydraulic Fracturing Improves Oil Production in the N'Dola Field, Offshore Angola, SPE 49108, presented at the SPE Annual Technical Conference and Exhibition held in New Orleans, Louisiana.

[10] Moore, L. P. and Ramakrishnan, H., 2006. Restimulation: Candidate Selection Methodologies and Treatment Optimization, SPE paper No. 102681, presented at the Annual Technical Conference and Exhibition, San Antonio, USA.

[11] Bustin, B. and Sierra, L. 2009. First regional selective packerless acid fracture stimulation with coiled tubing: a documented case history from Saudi Arabia, SPE paper No.120938, presented at the SPE/ICoTA Coiled Tubing and Well Intervention Conference and Exhibition, Woodlands, Texas, USA.

[12] Martin, A.N. and Economides, M.J., 2010. Best Practices for Candidate Selection, Design and Evaluation of Hydraulic Fracture Treatments, SPE 135669, SPE Production and Operations Conference and Exhibition held in Tunis, Tunisia.

[13] Mohaghegh, S.D., Gaskari, R., Popa, A., Salehi, I. and Ameri, S., 2005. Analysis of Best Hydraulic Fracturing Practices in the Golden Trend Fields of Oklahoma, SPE paper No. 95942, presented at Annual Technical Conference and Exhibition held in Dallas, Texas, USA.

[14] Abdulraheem, A., Ahmed, M., Vantala, A. and Parvez, T., 2007. Prediction of Rock Mechanical Parameters for Hydrocarbon Reservoirs Using Different Artificial Intelligence Techniques, SPE 105350-MS, SPE Middle East Oil and Gas Show and Conference, Kingdom of Bahrain.

[15] Steve Cuddy, 1997. The Application of the Mathematics of Fuzzy Logic to Petrophysicists, Society of Petrophysicists and Well Log Analysts.

[16] Shokir, E.M.EI-M. 2004. A Novel Model for Permeability Prediction in Uncored wells, SPE 87038MS, SPE Asia Pacific Conference on Integrated Modelling for Asset Management, Kuala Lumpur. 
[17] Mohaghegh, S.D., Popa, A., Gaskari, R., Wolhart, S. and Siegreid, R. 2004. Determining In-Situ Sress Profiles from Logs, SPE 90070-MS, SPE Annual Technical Conference and Exhibition, Houston, Texas.

[18] Cheng-Dang, Z, Wu, S.L., Mo, Z.C., Zhu, D.H. and Xu, Z.V. June 1994. Direct Identification of Hydrocarbon from Well Logs: A Neural Network Interpretation Approach, SPE 94-52, Annual Technical Meeting, Calgary, Alberta.

[19] Eaton, B.A. 1969. Fracture Gradient Prediction and Its Application in Oilfield Operation, JPT 1353.

[20] Zamora, M. 1989, New Method Predicts Gradient Fracture, Pet. Eng. Intl. 38.

[21] Koceir, M., and Tiab, D. 2000. Influence of stress and lithology on hydraulic fracturing in Hassi Messaoud reservoir, Algeria, SPE 62608, presented at the 2000 SPE/AAPG Western Regional Meeting held in Long Beach, California.

[22] Constant, W.D. and Bourgoyne, A.T. Jr. 1986. Method Predicts Frac Gradient for Abnormally Pressured Formations, Pet. Eng. Intl. 38.

[23] Pilkington, P.E., 1978 Fracture Gradient Estimates in Tertiary Basins, Pet. Eng. Intl. 138.

[24] Holbrook, P.W., Maggiori, D.A. and Hensley, R., RealTime Pore Pressure and Fracture Gradient Evaluation in All Sedimentary Lithologies, paper SPE 26791 presented at the 1993 SPE Offshore European Conference, Aberdeen,

[25] Anderson, R.A., Ingram, D.S. and Zanier, A.M. 1973 "Determining Fracture Pressure Gradients from Well Logs,” JPT 1259.

[26] Brennen, R.M. and Annis, M.R., : A New Fracture Gradient Prediction Technique That Shows Good Results in Gulf of Mexico Abnormal Pressure", paper SPE 13210 presented at the 1984 SPE Annual Technical Conference and Exhibition, Houston, 16-19 September

[27] Morales, R.H., 1989. Microcomputer Analysis of Hydraulic Fracture Behavior with a Pseudo-ThreeDimensional Simulator, SPEPE 69-74.

[28] Shadizadeh S.R. Habibnia B.A. and Syllabee R. 2009a, Investigation and Selection of Suitable Layers in Bangestan Reservoir for Hydraulic Fracturing Operation, Sceintia Iranica, Transactions C: Chemistry and Chemical Engineering. 16: 2, 149-160.

[29] Shadizadeh, S. R., Habibnia B. 2009b. Petrophysical Study on Selection of Potential Layers for Hydraulic Fracturing Operation. Presented at the 71st EAGE Conference \& Exhibition, Amsterdam.

[30] Sanaee R., Shadizadeh, S.R. and Riahi, M.A. 2010. Determination of the Stress Profile in a Deep Borehole in a Naturally Fractured Reservoir, International Journal of Rock Mechanics \& Mining Sciences, 47; 599-605. 